\title{
RECEPTIVE FIELD PROPERTIES IN THE CAT'S LATERAL GENICULATE NUCLEUS IN THE ABSENCE OF ON-CENTER RETINAL INPUT ${ }^{1}$
}

\author{
JONATHAN C. HORTON AND HELEN SHERK ${ }^{2}$ \\ Department of Neurobiology, Harvard Medical School, Boston, Massachusetts 02115
}

Received February 25, 1983; Revised July 25, 1983, Accepted September 29, 1983

\begin{abstract}
In the cat, lateral geniculate neurons and retinal ganglion cells can almost all be categorized as on-center (excited by light stimuli) or off-center (excited by dark stimuli). We have investigated how these cells are affected when a drug is applied to the retina that, in the mudpuppy, inactivates on-bipolar cells (Slaughter, M. M., and R. F. Miller (1981) Science 211: 182-185). This drug, D,L-2amino-4-phosphonobutyric acid (APB), is an analogue of glutamate. After injecting APB into the vitreous of the eye, we could record in the optic tract from fibers of off-center retinal ganglion cells that appeared normal in their responses, but we could find no fibers from on-center cells in the injected eye. In the lateral geniculate nucleus (LGN), the outcome was similar. Of a sample of 144 cells studied quantitatively, 13 had extremely poor responses and could not be characterized as onor off-center. The remaining 131 cells had off-centers and appeared largely normal. Their receptive field organization was unaltered: the field center was excited by dark (off) stimuli and inhibited by light, whereas the surround was inhibited by off stimulation. Of particular interest was the fact that the surrounds of many off-center cells could still be excited by light stimuli; thus, despite the probable inactivation of on-bipolar cells, not all on-responses in the LGN were abolished. As a group, off-center cells were somewhat less responsive then in control experiments. Except for this change, APB appeared to affect only on-center cells. We conclude that these latter cells were almost all silenced by the drug, with a small number perhaps retaining some weak and erratic response. This outcome suggests that the on and off pathways originating with the on- and off-bipolar cells of the retina remain fairly separate through the LGN: cells of one pathway do not provide detectable excitatory input to cells of the other.
\end{abstract}

The receptive field organizations of retinal ganglion and lateral geniculate cells in the cat were first described by Kuffler (1952) and Hubel and Wiesel (1961). They found two types of cells, having reciprocal receptive field organizations. In on-center cells, the field center was excited by light, whereas the surround was excited by dark stimuli; in off-center cells, the converse held, with the center being excited by dark stimuli. Since the center was much more effective in driving the cell than the

\footnotetext{
${ }^{1}$ We are grateful to Simon LeVay and Torsten Wiesel for generous support and encouragement throughout this project and for comments on the manuscript. We also thank Richard Masland for critical reading of the manuscript and Doris Ringer for secretarial help. This work was supported by National Institutes of Health Grant EY-R01-1960 to Simon LeVay and by National Institutes of Health Grant EY-00606 to Torsten Wiesel.

${ }^{2}$ To whom reprint requests should be addressed, at Department of Biological Structure, University of Washington School of Medicine, Seattle, WA 98195.
}

surround, these neurons have been considered to form two distinct pathways, one on and one off. Subsequent work has confirmed that more than $90 \%$ of retinal ganglion and geniculate cells have this sort of receptive field organization (Cleland and Levick, 1974; Wilson et al., 1976; Dreher and Sefton, 1979). At the level of primary visual cortex, however, the two pathways appear to converge: most cells in the cat's area 17 respond briskly to both light and dark stimuli (Hubel and Wiesel, 1962).

In the study described in this and the following paper, our goal has been to learn how the on and off pathways originating in the cat's retina contribute to the response properties of individual geniculate and cortical neurons. A pharmacological approach to this problem was offered by the results of Slaughter and Miller (1981). They found that D,L-2-amino-4-phosphonobutyric acid (APB) inactivated on-bipolar cells in the mudpuppy's retina, without affecting off-bipolar cells. They hypothesized that APB, a structural analogue of glutamate, binds to the postsynaptic receptors of on-bipolar cells, mimicking the 
hyperpolarizing effect of the photoreceptor transmitter. Neal et al. (1981) subsequently reported that APB inactivates the on-center responses of rabbit retinal ganglion cells, and preliminary experiments in which APB was injected intraocularly indicated that it might act similarly in cats (Horton, 1981).

At the level of the lateral geniculate nucleus (LGN), two questions of particular interest were considered. First, do intraocular injections of APB inactivate all oncenter cells? Second, do the response properties of offcenter cells remain completely unaffected? The answer to the first question is critical for interpreting the effects of intraocular APB on area 17. The second question is important both for interpreting the cortical results and for detecting possible interactions between on and off pathways within the LGN.

\section{Materials and Methods}

Surgery. Seven cats were prepared for acute electrophysiological recording using methods described in more detail elsewhere (LeVay and Sherk, 1981). Anesthesia was initially induced with ketamine, or ketamine and xylazine, injected intramuscularly. After all surgical procedures had been completed, the cat was paralyzed and respirated. A paralytic agent (gallamine triethiodide) and an anesthetic (sodium pentobarbital) were infused intravenously for the duration of the experiment. End-tidal $\mathrm{CO}_{2}$ was maintained between 3.5 and $4 \%$.

Eye injection. An electrode was placed in the LGN before APB eye injection in order to compare directly geniculate responsiveness before and after the drug took effect. A small incision was made in the lateral canthus of the right eye, and the eye was rotated far nasally to expose the sclera. A volume of $20 \mu \mathrm{l}$, containing $0.14 \mathrm{mg}$ of APB, was then injected. Given a vitreal volume of 2.5 $\mathrm{ml}$, this would yield a concentration of $300 \mu \mathrm{M}$. This was the lowest concentration tested at which consistent effects were observed.

One might worry that sufficient APB would be carried into the general circulation to affect neurons outside the retina directly. However, we found that intravenous APB injection had no effect on geniculate responses to light stimuli, even at high doses $(31 \mathrm{mg} / \mathrm{kg})$.

Possible retinal damage. It seemed possible that intraocular injections might damage the eye. Aside from readily detectable injuries caused by hitting the lens or a retinal blood vessel, the most likely source of trauma was increased intraocular pressure. Accordingly, we tested for pressure changes after injection in six eyes using an applamatic tonometer. No measurable increase was found over a 4 -hr period following injection.

Other evidence suggests that nonspecific damage did not occur. First, in most experiments we recorded from one geniculate cell immediately before and after an intraocular injection, and we could detect no change in either peak response or response duration to a standard stimulus. In one animal optic tract fibers were studied both before injection and repeatedly for 1.5 to $2 \mathrm{hr}$ afterwards, and they exhibited no decline in responsiveness. Finally, the effects of APB eventually wore off in every cat. The responses of both on- and off-center cells then appeared to be completely normal.
Time course of APB effects. The effectiveness of each APB injection was judged by testing multiple unit onresponses in the LGN to light stimulation. When these had vanished completely, we considered the APB to have taken effect. This took on the average $90 \mathrm{~min}$, although there was considerable variability, from $45 \mathrm{~min}$ to $3 \mathrm{hr}$. The variation was probably due to the exact position of the injection needle relative to the retina; in later experiments the tip was positioned closer to the retina, and the delay before the drug took effect was consistently shorter.

When these experiments were begun, it seemed possible that there might be large variations in APB concentration within the eye. It has been shown, however, that $20 \mu \mathrm{l}$ of fluorescein injected into the rabbit's eye result in an intravitreal concentration that is uniform across the retina after about $1 \mathrm{hr}$ (Cunha-Vaz and Maurice, 1967). One might expect APB, a small water-soluble molecule, to behave similarly. Our experience with APB suggests that it does diffuse readily within the vitreous, in that we did not find differential effects in different parts of the LGN or cortex in one experiment.

What was unexpected was the prolonged duration of the drug's effectiveness. It eventually wore off after a variable interval, ranging from 5 to $20 \mathrm{hr}$, but typically about $12 \mathrm{hr}$. This made it essential to monitor geniculate multiple unit activity frequently for any sign of returning on-response; if detected, more APB was injected. On average, two injections were made per experiment.

Recording. The activity of single units was isolated with tungsten microelectrodes (Hubel, 1957). No marking lesions were made, since the sequence of eye dominance and the location of receptive fields were sufficient to determine in what layer each cell was located. Receptive fields were situated 3 to $15^{\circ}$ from the area centralis.

Stimulus presentation. All receptive fields were first plotted with a hand-held stimulator. For quantitative data collection, light spots of different sizes (given in Fig. 5) were used. For most cells, response histograms were obtained using each diameter. The reflectance of the tangent screen was $1.93 \mathrm{~cd} / \mathrm{m}^{2}$, and the stimuli were 1.1 log units brighter. Spikes were passed through a window discriminator and compiled into histograms with 480 bins by a small computer. In each trial the spot stimulus was on for the first $4 \mathrm{sec}$ and off for the subsequent 4 sec; there were 10 trials per histogram. Similar histograms were made of cell responses to light annuli, whose reflectances were equal to those of the light spot stimuli used. A range of sizes was tested for each cell, although the outer diameters were always $20^{\circ}$. The computer also stored information regarding response variability in the form of standard deviations, computed separately for the number of spikes fired during the on and off portions of each histogram.

Cell classification. The responses of most cells were classified as linear or nonlinear by the use of square wave gratings of $0.5,1$, or 2 cycles per degree. We searched for a grating position where contrast reversals elicited no response (null position; Enroth-Cugell and Robson, 1966). If found, the cell was classified as linear; if the cell lacked a null position and gave a frequency doubled response at some positions, it was classed as nonlinear. 


\section{Results}

Recordings from optic tract. The main goal of our recordings from the optic tract was to confirm that in the cat, as in the mudpuppy and rabbit (Slaughter and Miller, 1981; Neal et al., 1981), APB blocks the on-center responses of retinal ganglion cells. In four cats APB was injected intraocularly, and multiple unit activity was recorded in the LGN until the onset of the drug's action. The electrode was then moved forward a few millimeters to make vertical penetrations through the optic tract. Of 38 optic tract fibers driven by an APB-injected eye, none gave definite on-center responses. In contrast, in normal optic tract one would expect to encounter nearly as many on-center as off-center fibers (Rodieck and Stone, 1965; Hammond, 1974; Bullier and Norton, 1979; Wässle et al., 1981a, b). In our sample from control experiments, the numbers of on- and off-fibers were similar, 21 and 31 , respectively.

Most fibers in APB-injected cats (28) appeared to have typical off-center properties. They responded vigorously to a small light spot turned off in the receptive field center, and their maintained discharge was suppressed when the spot was turned on. Large spots were much less effective. The responses of these cells could readily be classified as linear or nonlinear when tested with a square wave, counter-phase grating (see "Materials and Methods"), suggesting that the linear and nonlinear spatial summation that distinguishes $\mathrm{X}$ from Y cells (Enroth-Cugell and Robson, 1966) was still present after APB injection. Twelve fibers were studied quantitatively. Their peak response averaged 177 spikes/sec, which was less than the average obtained from our normal geniculate cells and is thus probably also less than what one would find in normal optic tract. Spontaneous activity levels, on the contrary, were high, averaging 71 spikes/ sec. Curves that plotted response as a function of spot size all showed a decline with larger diameters, confirming that receptive fields had inhibitory surrounds.

The remaining 10 units were strikingly abnormal. They had little spontaneous activity and gave only feeble, erratic responses to visual stimulation. Only with considerable patience was it possible to identify a region of the visual field where responses could be evoked. Even then, responses were so inconsistent that it was difficult to define their receptive fields. Histograms were made for five of these cells, primarily to convince ourselves that there was indeed a response. Sometimes they responded at light on, sometimes at off, and, not uncommonly, at both. In general, a large spot was necessary to obtain any response; the presence of center-surround organization could not be ascertained.

Geniculate on-center cells. As for the optic tract, the principal finding in the LGN was that APB abolished all on-center responses. In normal LGN, one would expect to encounter roughly equal numbers of on-center and off-center cells (Cleland and Levick, 1974; Wilson et al., 1976; Bullier and Norton, 1979; Dreher and Sefton, 1979); in control experiments, 33 cells had on-centers and 34 had off-centers. But after APB injection into one eye, we could find no cells with on-center responses in the corresponding geniculate laminae (see Table I). The change was also obvious in the massed response of mul- tiple units recorded with a large electrode: a small light spot elicited a brisk response when turned off but no response at all when turned on. If we happened to be recording activity from cells with a high maintained firing rate, there was an obvious suppression of firing when the stimulus came on, but no other change.

Direct evidence that APB inactivated on-center cells came from 11 neurons studied both before and after injection; in all cases, their responses were suppressed by APB. Figure 1 shows an on-center Y cell's response before the eye injection and a histogram of its firing to the same stimulus, a $0.75^{\circ}$ spot, $45 \mathrm{~min}$ after $0.14 \mathrm{mg}$ of APB was injected. It retained a low level of spontaneous activity but had no response.

Types of geniculate cells encountered. In the geniculate laminae receiving input from the APB-injected eye, cells could be grouped into three categories: off-center cells, cells with responses too poor to allow identification, and unresponsive cells. Neurons resembling normal off-center cells constituted the bulk of our quantitatively studied sample, 131 of 177 cells. Their distribution among the geniculate laminae is shown in Table I. In the poorly responsive category were 13 cells that gave weak and variable responses, sometimes to off and sometimes to on. Often these responses occurred at latencies over 300 msec, very much longer than normal. As with abnormal optic tract fibers, we generally had difficulty in localizing their receptive fields. Altogether, these were unlike any

TABLE I

Cells studied quantitatively in different divisions of the lateral geniculate nucleus

Division of Lateral Geniculate Nucleus

$\begin{array}{lllll}\text { A } & \text { A1 } & \text { C }^{a} & \text { MIN } & \begin{array}{c}\text { Optic } \\ \text { Radiation }\end{array}\end{array}$

With APB

Number of off-center cells

Number of on-center cells

Control $^{b}$

Number of off-center cells

Number of on-center cells

${ }^{a} \mathrm{C}$ includes parvocellular $\mathrm{C}$ laminae.

${ }^{b}$ Control sample includes nine cells not studied quantitatively.

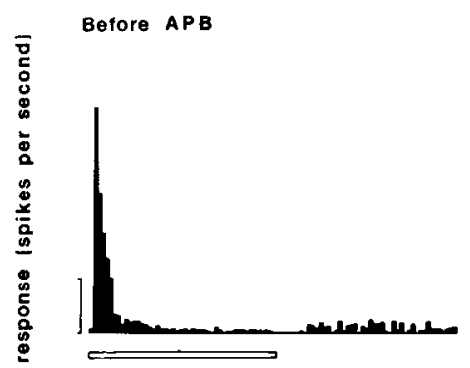

After APB

Figure 1. A geniculate on-center Y cell's response before and after the right eye was injected with APB. On the left is a poststimulus time histogram showing the cell's response to a small light spot $\left(0.75^{\circ}\right.$ diameter) turned on for $4 \mathrm{sec}$ (indicated by horizontal bar) and off for $4 \mathrm{sec}$. On the right is the cell's activity when the same stimulus was presented 45 min after APB injection; it showed no response. These histograms and all subsequent ones illustrated were compiled from 10 trials each. Calibration bars: 50 spikes/sec. 
cells that we have found in normal LGN (excluding the parvocellular $\mathrm{C}$ layers). Finally, 14 completely unresponsive cells, recognized by an occasional spontaneous spike, were encountered. Probably many more were overlooked.

Center responses of off-center cells. It was difficult to tell from casual observations whether off-center cells in APB-affected laminae were entirely normal in their responses. In some respects, they seemed so. Most (85 of 98 tested) could be shown to summate linearly or nonlinearly in response to a counter-phased, square wave grating. We suspect, but cannot prove, that these corresponded to the $\mathrm{X}$ and $\mathrm{Y}$ cells found in normal LGN (Derrington and Fuchs, 1979; So and Shapley, 1979, 1981). In agreement with the reports of these authors and of Cleland et al. (1971b), linear cells often had sustained responses, and nonlinear cells almost always had transient ones. Histograms of the responses of typical linear and nonlinear cells to a $0.5^{\circ}$ light spot, shown in Figure 2, are qualitatively indistinguishable from ones obtained from normal LGN.

In our initial recordings in the LGN after APB eye injections, we had the impression that the responses of off-center neurons were somewhat depressed. To test this, the peak responses of 113 off-center cells recorded after APB injection were compared with those of 61 geniculate cells from control experiments (the latter included responses from on-center and off-center cells, since these did not differ statistically). These are shown in Figure 3 on the left side. The median peak response among APB-affected cells was 144 spikes/sec and that for control cells was 205 spikes/sec (analysis of variance showed the difference to be significant with $p<0.001$ ). For the reasons given under "Materials and Methods," we consider it unlikely that this decline was due to nonspecific retinal damage.

On the right side of this figure, the APB-affected sample is broken down by cell type. Both linearly and nonlinearly summating cells showed depressed responses. The least responsive cells (bottom histogram)

A

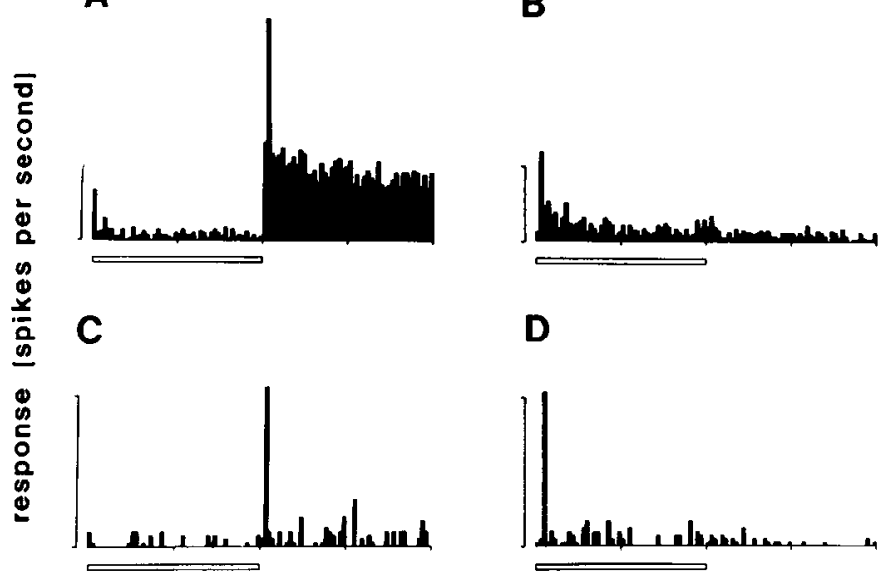

Figure 2. Responses of two off-center cells to spots and annuli after APB injection. $A$, The response of a linearly summating cell to a $0.5^{\circ}$ spot. $B$, Its on-response to a light annulus with an inner diameter of $2.1^{\circ}$. C, A nonlinearly summating cell's response to a $0.5^{\circ}$ spot. $D$, Its on-response to a light annulus with an inner diameter of $2.1^{\circ}$. This response was about as vigorous as that to center stimulation. Calibration bars: 40 spikes/sec.
A

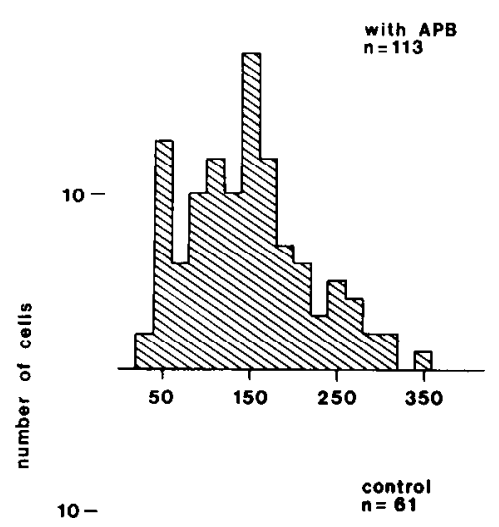

B
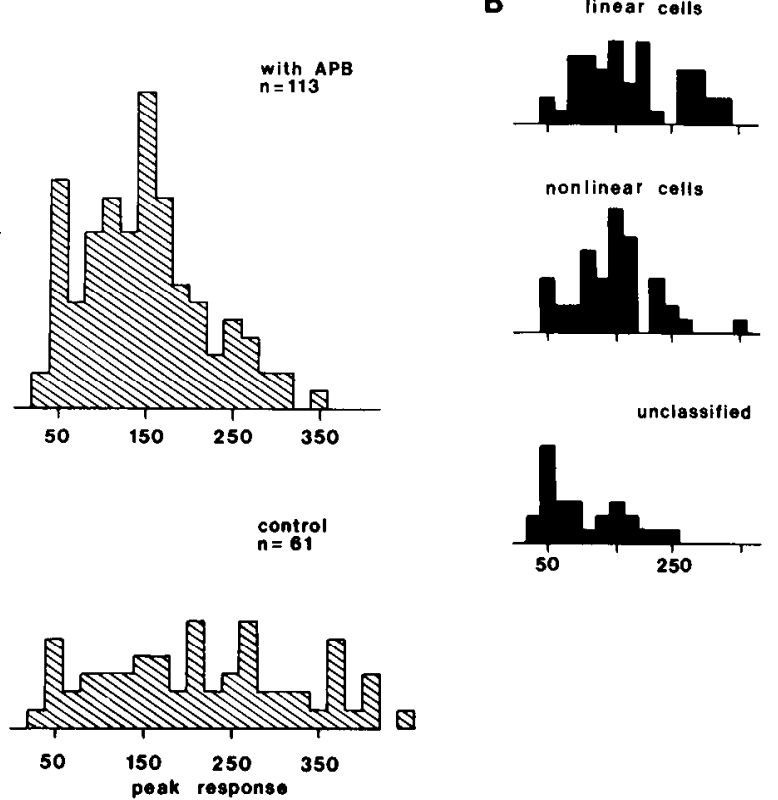

Figure 3. Response strength of geniculate cells with and without APB. Peak response, given in spikes per second, was taken to be the largest response (averaged over $1 / 30 \mathrm{sec}$ ) that could be elicited by an optimal spot stimulus. $A$, Above are peak responses of 113 off-center cells studied after intraocular APB injection. The median value was 144 spikes/sec. Below are peak responses of on- and off-center cells in normal LGN. The median was 205 spikes/sec. $B$, The APB-affected sample is broken down according to cell type. The least responsive cells generally could not be classified.

remained unclassified, since their responses to gratings were too poor to indicate whether their summation was linear.

Latencies from stimulus onset to initial response for APB-affected cells were the same as for normal geniculate cells (the average in both cases was about $100 \mathrm{msec}$ ), so that APB appeared to reduce off-center responses without delaying them. In addition, responsiveness (number of spikes per trial) was as consistent in the APB-affected as in the control sample (analysis of variance, $d f=127$ ).

Off-center cells are normally inhibited by illumination of the receptive field center, and this was also true of most cells in the APB-affected LGN (for example, Fig. 2). Some, however, appeared to have abnormally weak, or possibly no, center inhibition. While a light spot illuminated the field center they fired in a characteristically bursty fashion, so that their net activity during this time was higher than their spontaneous activity. Figure 4 shows the behavior of two such cells. It is hard to define a borderline between normal and subnormal center inhibition, since many off cells in control LGN are not completely inhibited by a light spot, but about 9 of 81 cells seemed clearly abnormal in this regard. (For the remainder of our sample information about spontaneous firing rates was not available; thus, we could not evaluate receptive field center inhibition.)

Surround responses of off-center cells. So far we have considered only center responses to spots of optimal size. Geniculate receptive fields typically have surround in- 


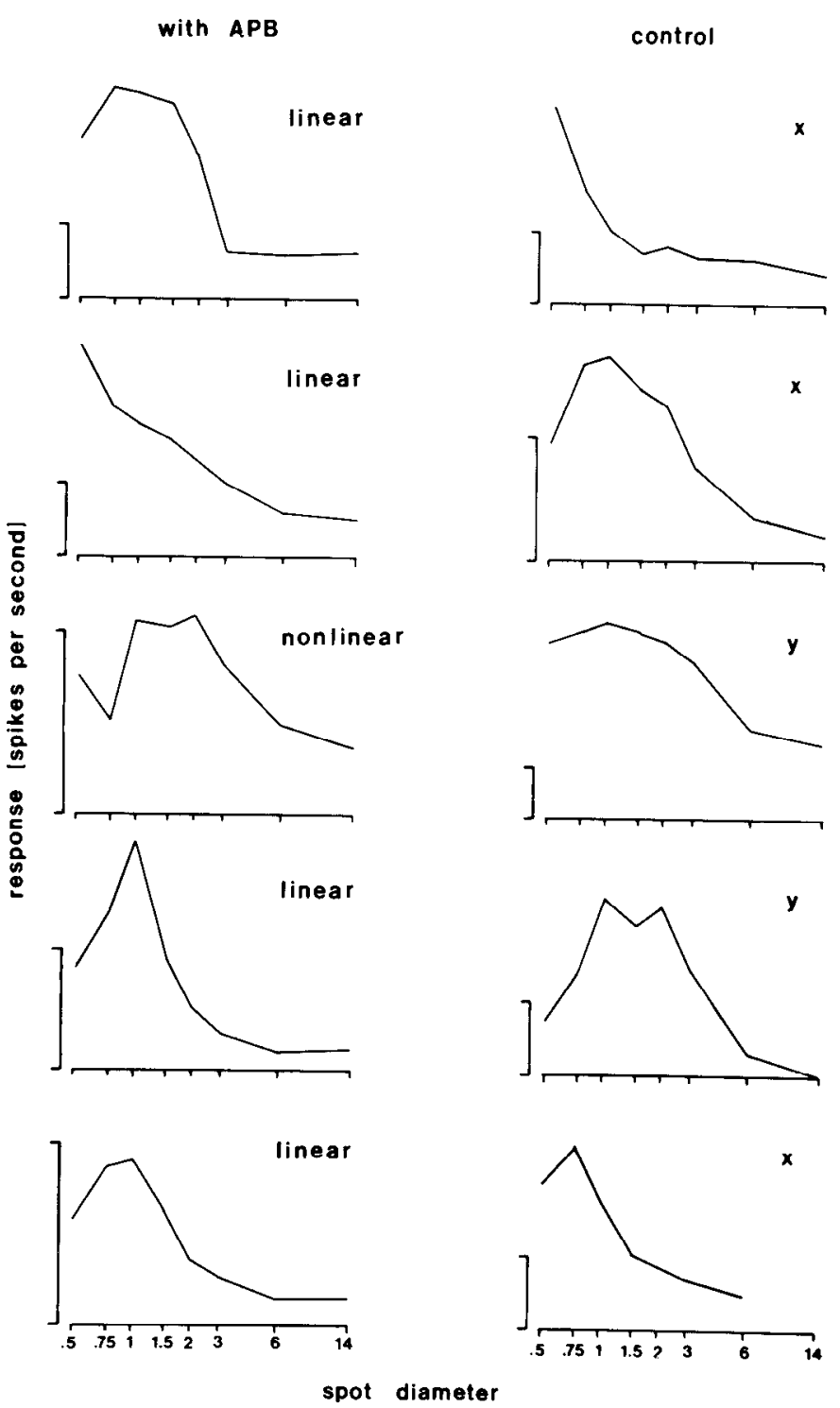

Figure 4. Two off-center cells' responses after APB injection, showing abnormally high activity while the light spot was turned on. Both were putative $\mathrm{X}$ cells, having linear summation. Spot diameter was $1^{\circ}$ for $A$ and $1.5^{\circ}$ for $B$. Calibration bars: 40 spikes/sec.

hibition, so that their responses to larger spots are worse or completely absent (Hubel and Wiesel, 1961). To see whether these surrounds were affected by APB, for 110 cells we measured response as a function of spot size.

Most (94 cells) showed the usual decline in response to spot sizes increased above optimal. Some typical curves plotting response versus spot size are given in Figure 5, along with ones from normal geniculate cells. There is no obvious difference between the normal and APB-affected cells. To be sure of this, we found the spot size at which responses had fallen to half of maximum for each cell and then took the difference between this and the optimal spot size. This gave us an estimate of the effectiveness of surround inhibition for each cell. By this measure, such inhibition was equally strong in these cells and in 53 cells from control experiments, so that it appears that most APB-affected off-center cells retain the normal balance between center excitation and surround inhibition. In addition, there was no significant increase in the number of cells having little or no surround inhibition.

A question of considerable interest is whether the surrounds of off-center cells still give on-responses after APB eye injection. Sixty-six cells were tested with light annuli, and most (58 cells) were found to have onsurround responses. Two of these responses are illustrated on the right side of Figure 2. On-surround responses were relatively vigorous, with the median cell's response being $39 \%$ of its best off-center response. In Figure 6, surround responses have been plotted as percentages of best center responses for both the APBaffected and control samples; statistically, there is no difference between the two groups.

Maintained activity. Intraocular APB had no obvious effect on the maintained firing rate of off-center cells; the medians for the experimental and control samples were 7 and 5.3 spikes/sec, respectively. The effect of APB on on-center cells' maintained activity was more difficult to judge. We can at least say that it was diminished or lost in most cells, since neurons having maintained but no evoked activity were rare. However, the on-center cell illustrated in Figure 1 retained some maintained firing $45 \mathrm{~min}$ after APB injection.

\section{Discussion}

APB proved to be remarkably selective for the on pathway in the cat, in agreement with Slaughter and

Figure 5. Curves plotting response as a function of spot size for five off-center cells affected by APB and five cells from normal LGN. Each cell was tested with eight different spot sizes (their diameters are given on the abscissa). All show surround inhibition, with diminishing responses to large spots. The curves from normal and APB-affected LGN are indistinguishable.

Miller's (1981) findings in the mudpuppy. In neither the optic tract nor the LGN were cells with clear on-center responses encountered after the drug was injected intraocularly. Most of the cells that could be driven in the LGN $(91 \%)$ had responses and receptive field characteristics that were qualitatively indistinguishable from those of normal off-center cells.

The most obvious interpretation of these results is that APB inactivates on-center retinal ganglion cells and, consequently, on-center geniculate cells. That this happens in the retina has been confirmed by J. Bolz, $\mathrm{H}$. Wässle, and P. Thier (submitted for publication). Regarding the LGN, however, we cannot rule out the possibility that some on-center cells are not inactivated but only lose their on-center responses. If they simply retained their excitatory off-surrounds, one would expect to find that some responsive cells in the LGN had no 


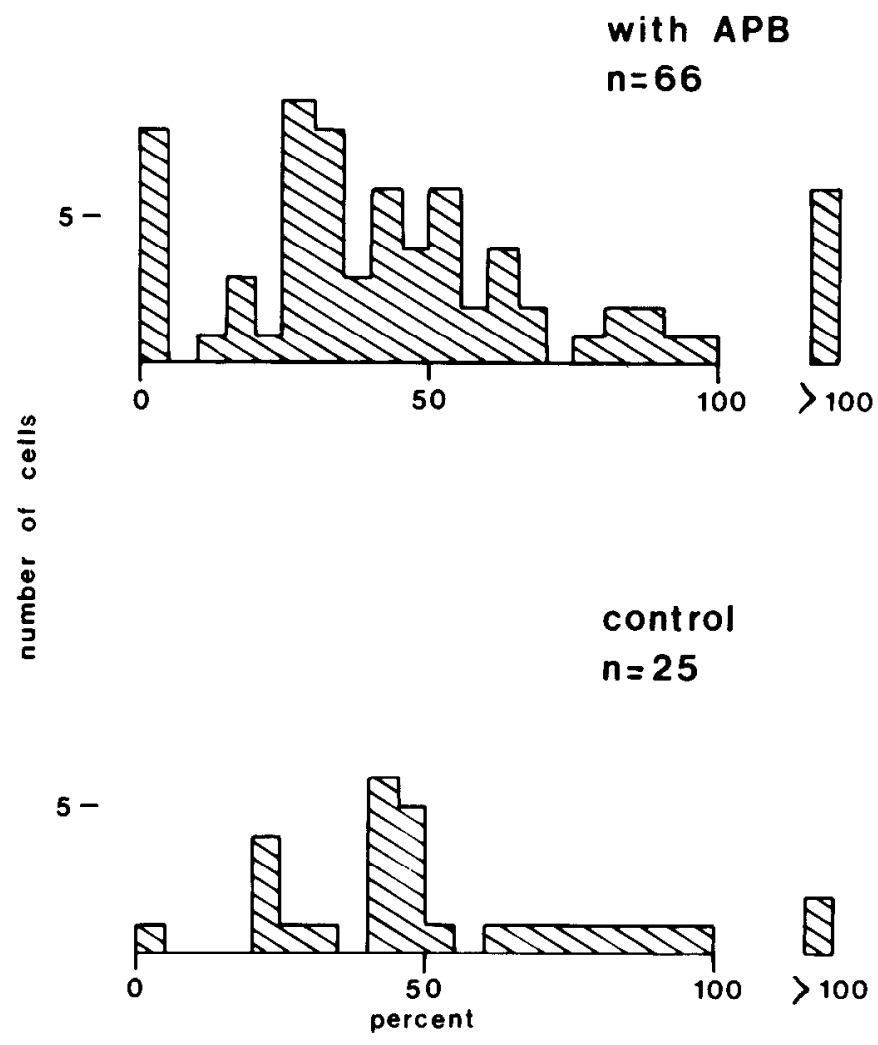

Figure 6. Excitatory surround response as a percentage of center response for cells from APB-affected (upper histogram) and control (lower histogram) LGN. Each cell's response to an optimal annulus is expressed as a percentage of its response to an optimal center spot. Center responses were strong for most cells; the median percentages were $39 \%$ for the APB-affected sample and $45 \%$ for the control sample. Surround responses appeared to be equally vigorous in the two samples.

surrounds, excitatory or inhibitory, and responded best to large off stimuli; these would be the predicted characteristics of the surviving off-surrounds. We did not find such a class of cells, however. If on-center cells remained responsive, they must have somehow acquired the receptive field organization of off-center cells. We view this as exceedingly unlikely. First, it is improbable that such cells receive afferents that would enable them to give vigorous off-center responses. There is good evidence that off-center retinal axons do not have any direct input to on-center geniculate cells. Whenever both a geniculate cell and its retinal afferent have been studied simultaneously, the two have been found to be of the same center type (Hubel and Wiesel, 1961; Cleland et al., 1971a, b; Singer et al., 1972; So and Shapley, 1981). In addition, the interpretation described above is unappealing theoretically, since one must postulate the existence of inputs to each geniculate cell that would only function in the unlikely event that on-center retinal cells were inactivated.

The small population of abnormal, poorly responsive cells found in the LGN after intraocular APB injections might correspond to on-center cells that had not been entirely inactivated. However, they might equally well have been off-center cells whose retinal inputs were, for unknown reasons, affected by the drug. From the point of view of the cortex, these cells were probably of little significance, since their responses were so poor that it is hard to imagine them driving cells in area 17.

The situation in the retina closely resembles that in the LGN. Both our limited optic tract recordings and the more extensive results of J. Bolz, H. Wässle, and P. Thier (submitted for publication) indicate that the responses of off-center retinal ganglion cells are somewhat depressed by APB, although their receptive field properties remain normal. The only change in the retina reported by Bolz et al. that was not also obvious in our geniculate recordings was an increase in maintained activity. The close agreement between the results of the two studies is reassuring, since the methods used were quite different. Bolz et al. iontophoresed APB onto a small patch of retina, and they were able to study single cells before and during application of the drug. Thus, they avoided the major drawback of our approach, the necessity of comparing samples of experimental and control cells.

Our main finding, that on-center responses in the I.GN are lost, agrees with Schiller's (1982) results in the monkey and Knapp and Mistler's (1982) in the rabbit. In these animals, however, in contrast to our results in the cat, no consistent reduction in off-center cell responses was observed. Since these authors used a different technique (continuous perfusion of the vitreal cavity with a solution containing APB), it is difficult to say whether the discrepancy reflects an actual species difference.

A more perplexing difference between the monkey and the cat concerns the sensitivity of different cell types to APB. In the monkey, cells in the magnocellular laminae are markedly more resistant to APB than ones in the parvocellular laminae (Schiller, 1982). Magnocellular cells have been considered homologous to $\mathrm{Y}$ cells on the basis of their response latencies to optic chiasm shock, their temporal response properties, and their field sizes (Dreher et al., 1976; Sherman et al., 1976; Schiller and Malpeli, 1978). Therefore, we searched the cat's LGN, including layer $\mathrm{C}$ and the medial interlaminar nucleus, for a population of APB-resistant cells showing nonlinear, Y-like summation, but we could find none. Similarly, there were no clear differences in the effects of APB on off-center cells that summated nonlinearly as opposed to those that summated linearly. Assuming that these corresponded to $\mathrm{Y}$ and $\mathrm{X}$ cells, respectively (excluding those found in the C layers, which might be confused with $W$ cells; Sur and Sherman, 1982), we would conclude that APB in the cat does not have differential effects on these two cell classes.

It is particularly interesting that the on-surrounds of off-center geniculate cells appeared to be as responsive as normal. Evidently, on-center retinal afferents make no major excitatory contribution to these surrounds. There was also no obvious contribution from these afferents to surround inhibition, although we did not distinguish between the effect of the more central, antagonistic surround and that of the peripheral, purely suppressive surround (Cleland et al., 1971b; Levick et al., 1972); it is quite plausible that the latter normally does receive oncenter inhibition (see, for example, Singer et al., 1972). The case regarding the excitatory surround responses of on-center cells appears to be similar. As mentioned above, we could find no evidence that off-surrounds 
survived APB injections, which suggests that these do not receive a major driving input from off-center retinal afferents. Thus, the essential features of retinal and geniculate center-surround organization appear to depend upon only one class, on or off, of bipolar cells.

In summary, following APB eye injection the geniculate population consisted of off-center cells having essentially normal receptive fields, and a small number of poorly responsive, abnormal cells. These results provide the groundwork for interpreting changes in receptive field properties found in area 17 after intraocular APB injection, as described in the following paper (Sherk and Horton, 1984).

\section{References}

Bullier, J. H., and T. T. Norton (1979) X and Y relay cells in cat lateral geniculate nucleus: Quantitative analysis of receptive-field properties and classification. J. Neurophysiol. 42: 244-273.

Cleland, G. B., and W. R. Levick (1974)Brisk and sluggish concentrically organized ganglion cells in the cat's retina. J. Physiol. (Lond.) 240: 421-456.

Cleland, B. G., M. W. Dubin, and W. R. Levick (1971a) Simultaneous recording of input and output of lateral geniculate neurons. Nature (New Biol.) 231: 191-192.

Cleland, B. G., M. W. Dubin, and W. R. Levick (1971b) Sustained and transient neurones in the cat's retina and lateral geniculate nucleus. J. Physiol. (Lond.) 217: 473-496.

Cunha-Vaz, J., and D. Maurice (1967) The active transport of fluorescein by the retinal vessels and the retina. J. Physiol. (Lond.) 191: 467-486.

Derrington, A. M., and A. F. Fuchs (1979) Spatial and temporal properties of $\mathrm{X}$ and $\mathrm{Y}$ cells in the cat lateral geniculate nucleus. J. Physiol. (Lond.) 293: 347-364.

Dreher, B., and A. J. Sefton (1979) Properties of neurons in the cat's lateral geniculate nucleus: A comparison between medial interlaminar and laminated parts of the nucleus. J. Comp. Neurol. 183: 47-64.

Dreher, B., Y.Fukada, and R. W. Levick (1976) Identification, classification and anatomical segregation of cells with $\mathrm{X}$-like and $Y$-like properties in the lateral geniculate nucleus of oldworld primates. J. Physiol. (Lond.) 258: 433-452.

Enroth-Cugell, C., and J. G. Rohson. (1966) The contrast sensitivity of retinal ganglion cells of the cat. J. Physiol. (Lond.) 187: 517-552.

Hammond, P. (1974) Cat retinal ganglion cells: Size and shape of receptive field centres. J. Physiol. (Lond.) 242: 99-118.

Horton, J. C. (1981) Effect of blocking retinal on-channels with aminophosphonobutyric acid (APB) on the cat visual system. Soc. Neurosci. Abstr. 7: 24.

Hubel, D. H. (1957) Tungsten microelectrode for recording from single units. Science 125: 549-550.

Hubel, D. H., and T. N. Wiesel (1961) Integrative action in the cat's lateral geniculate body. J. Physiol. (Lond.) 155: 385398.

Hubel, D. H., and T. N. Wiesel (1962) Receptive fields, binoc- ular interaction and functional architecture in the cat's visual cortex. J. Physiol. (Lond.) 160: 106-154.

Knapp, A. G., and L. Mistler (1982) 2-Amino-4-phosphonobutyric acid reveals independence of on and off channels in rabbit lateral geniculate nucleus. Soc. Neurosci. Abstr. 8: 262 .

Kuffler, S. W. (1952) Neurons in the retina: Organization, inhibition and excitation problems. Cold Spring Harbor Symp. Quant. Biol. 17: 281-292.

LeVay, S., and H. Sherk (1981) The visual claustrum of the cat. I. Structure and connections. J. Neurosci. 1: 956-980.

Levick, W. R., B. G. Cleland, and M. W. Dubin (1972) Lateral geniculate neurons of cat: Retinal inputs and physiology. Invest. Ophthalmol. 11: 302-311.

Neal, M. J., J. R. Cunningham, T. A. James, M. Joseph, and J. F. Collins (1981) The effect of -2-amino-4-phosphonobutyric acid (APB) on acetylcholine release from the rabbit retina: Evidence for on-channel input to cholinergic amacrine cells. Neurosci. Lett. 26: 301-305.

Rodieck, R. W., and J. Stone (1965) Analysis of receptive fields of cat retinal ganglion cells. J. Neurophysiol. 28: 833-849.

Schiller, P. H. (1982) Central connections of the retinal ON and OFF pathways. Nature 297: 580-583.

Schiller, P. H., and J. G. Malpeli (1978) Functional specificity of lateral geniculate nucleus laminae of the rhesus monkey. J. Neurophysiol. 41: 788-797.

Sherk, H., and J. C. Horton (1984) Receptive field properties in the cat's area 17 in the absence of on-center geniculate input. J. Neurosci. 4: 381-393.

Sherman, S. M., J. R. Wilson, J. H. Kaas, and S. V. Webb (1976) X-and Y-cells in the dorsal lateral geniculate nucleus of the owl monkey (Actus trivigatus). Science 192: 475-477.

Singer, W., E. Pöppel, and O. D. Creutzfeldt (1972) Inhibitory interaction in the cat's lateral geniculate nucleus. Exp. Brain Res. 14: 210-226.

Slaughter, M. M., and R. F. Miller (1981) 2-Amino-4-phosphonobutyric acid: A new pharmacological tool for retinal research. Science 211: 182-185.

So, Y. T., and R. Shapley (1979) Spatial properties of X and Y cells in the lateral geniculate nucleus of the cat and conduction velocities of their inputs. Exp. Brain Res. 36: 533-550.

So, Y. T., and R. Shapley (1981) Spatial tuning of cells in and around the lateral geniculate nucleus of the cat: $\mathrm{X}$ and $\mathrm{Y}$ relay cells and perigeniculate interneurons. J. Neurophysiol. 45: $107-120$.

Sur, M., and S. M. Sherman (1982) Linear and nonlinear Wcells in C-laminae of the cat's lateral geniculate nucleus. J. Neurophysiol. 47: 869-884.

Wässle, H., B. B. Boycott, and R. -B. Illing (1981) Morphology and mosaic of on- and off-beta cells in the cat retina and some functional considerations. Proc. R. Soc. Lond. (Biol.) 212: $177-195$.

Wässle, H., L. Peichl, and B. B. Boycott (1981) Morphology and topography of on- and off-alpha cells in the cat retina. Proc. R. Soc. Lond. (Biol.) 212: 157-175.

Wilson, P. D., M. H. Rowe, and J. Stone (1976) Properties of relay cells in the cat's lateral geniculate nucleus: A comparison of W-cells with X-and Y-cells. J. Neurophysiol. 39: 1193-1209. 